\section{Walking, body mass index, and self-rated health in a representative sample of Spanish adults}

\author{
Caminar, índice de masa corporal y percepción de \\ la salud en una muestra representativa \\ de la población adulta española
}

\section{Caminhada, índice de massa corporal e percepção de saúde em amostra representativa da população adulta espanhola}

Vicente Romo-Perez 1 Dilia Souto 2 Jorge Mota 3

\begin{abstract}
Obesity and physical inactivity (PI) are risk factors for chronic diseases and are associated with lifestyle and environmental factors. The study tested the association between PI, body mass index (BMI), and self-rated health in a representative sample of the Spanish adult population $(N=21,486)$. The sample included $41.5 \%$ men, with mean age 52.3 years $( \pm 18.03)$, and age range 20-82 years. Prevalence of overweight/obesity was $34.2 \% / 12.7 \%$ in women and $52.1 \% / 12.7 \%$ in men ( $p<0.001$ for obesity in both sexes). 53\% of women and $57.5 \%$ of men met recommended levels of physical activity by walking ( $\geq 150$ minutes/week). According to logistic regression analysis, individuals that walked less had higher risk of overweight or obesity. Data from the population-based surveillance study support suggestions that regular walking by adults is associated with positive self-rated health and better BMI profile. Obesity and low/very low self-rated health have low prevalence rates to meet the recommendations.
\end{abstract}

Exercise; Gender Identity; Motor Activity; Adult

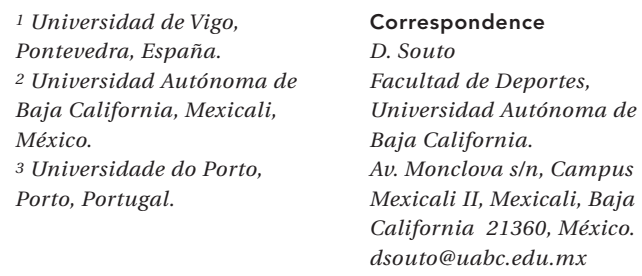

1 Universidad de Vigo, Pontevedra, España.

2 Universidad Autónoma de Baja California, Mexicali, México.

3 Universidade do Porto,

Porto, Portugal. 


\section{Introduction}

The lack of physical activity (PA) is an important risk factor for several diseases, such as coronary heart disease, hypertension, dyslipidemia, obesity, type 2 diabetes, certain types of cancer, osteoporosis, arthritis, anxiety and depression. Having a meagre health budget is an enormous factor 1, and lack of PA has a direct relation to premature mortality 2 as well as health-related quality of life ${ }^{3}$. Physical inactivity has a major health effect worldwide, and increasing activity behavior could improve a population's health 4 . Therefore, physical inactivity is recognized as a major public health concern since it is the fourth most significant cause of death worldwide 5 . Since the 1970s, several international organizations have developed PA guidelines for healthy adults. These guidelines have changed significantly in the past years. The World Health Organization physical activity guidelines recommend the accumulation of 150 minutes or more of moderate-intensity aerobic PA per week or 75 minutes of vigorous-intensity aerobic PA per week ${ }^{6}$. However, despite the benefits of regular PA on health, the prevalence of accomplishment with the recommended levels of PA is low in many developed countries 7. Previous data of a Spanish population based on a Eurobarometer study showed that $71 \%$ of Spaniards reported to be active once a week or more 8 .

On the other hand, overweight and obesity has been described as a growing problem worldwide and has reached epidemic concerns in European countries 9 including Spain 10 . Furthermore, a link between PA, obesity status and healthrelated quality of life has been established 11 . Therefore, the need to increase PA levels on a population basis is considered a public health priority. Walking can help physically inactive populations, increasing an active lifestyle. Additionally it is a feasible way of travelling, with virtually no cost and is associated with several health benefits, according to the guidelines of daily physical activity 12 . Indeed, walking as a way to get to and from places or just for recreation purposes may contribute significantly to adults' total PA. Although positive evidence between PA and walking with health outcomes are growing, most of the research has been carried out in the U.S.A., Australia and Canada 13. Consequently, studies and analysis in other countries and populations are necessary because it is not clear whether the associations observed in those countries are generalizable to other populations 14. Further, self-rated health was consistently associated with physical health status as well as an important independent predictor of risk of car- diovascular disease and all-cause mortality 15 Indeed, it was suggested that self-rated health is a powerful indicator of a population's overall wellbeing because its lower ratings (i.e., fair or poor) are strongly predictive of future morbidity, mortality, functional decline, and health care utilization 16. Less plausibly, other studies suggest that utilitarian walking is not related to BMI 17 .

Nonetheless, to the best of our knowledge, no studies have been published about the association of those factors in a representative sample of the Spanish population. Therefore, the aims of this study were twofold: (1) to describe PA prevalence; and (2) to examine associations between physical activity, body mass index (BMI) and self-rated health in a Spanish National representative sample.

\section{Methods}

\section{Study design}

Our empirical analysis was based on data drawn from the 2009 European Health Survey (EES09) conducted by the National Statistics Institute (NSI) and the Ministry of Health, Social Services and Equality of the Spanish Government. The questionnaires targeted a resident population in Spain. Face-to-face interviews were carried out between April 2009 and March 2010. This crosssectional study employed a representative sample of the Spanish population, and consisted of 22,188 interviews. But for our study we deleted the individuals under the age of $20(\mathrm{~N}=21.486)$.

\section{Sample}

We used data from individuals aged 20 years of age and older (age range: 20-82 years), totaling 21,486 individuals. The EES in Spain was carried out over a population of 46,745,807 individuals.

The sampling process was carried-out in all Spanish provinces. The survey used a three-stage sampling with first-stage-unit stratification. The first-stage units were census sections. The second-stage units were dwellings. Lastly, an adult person has been selected within each household. The stratification criterion used was the size of the municipality divided into 6 categories. The questionnaires were completed by conducting personal home interviews. Details about the survey can be accessed from the NSI web site 18 .

\section{Variables}

Walking: walking was assessed using the International Physical Activity Questionnaire -short ver- 
sion- (IPAQ) and was expressed in minutes per week ( $\mathrm{min} /$ week). The respondents were classified low walkers (walking for less than $150 \mathrm{~min} /$ week) and regular walkers (walking for $150 \mathrm{~min} /$ week or more) allowing this classification to split the sample according to PA recommendations 19.

Educational level: participants were asked how many school years they had completed. Then, educational level was categorized into four groups: (1) no formal education; (2) first grade school; (3) secondary education; and (4) higher education. This categorization was described elsewhere in a Spanish population.

Anthropometric measures: BMI was calculated from self-report weight and height. BMI was divided in three categories: normal weight (18.5kg.m-2 $\geq$ BMI < 25kg.m-2); overweight (25kg.m-2 $\geq$ BMI $<30 \mathrm{~kg} \cdot \mathrm{m}^{2}$ ) and obese (BMI $\geq$ 30kg.m-2) 20 .

Self-rated health: participants were asked to assess their own health status by responding to the question: "in general, how would you rate your health?" Items are scored on a Likert scale with 1 = "very poor" to 5 = "very good". This measure was divided into three categories: very poor/ poor, fair and good/very good.

\section{Statistical analysis}

Descriptive statistics were used to characterize the sample (mean, median, standard error $\left(s_{x}\right)$ and $95 \%$ confidence interval $(95 \% \mathrm{CI})$. The $t$-tests were used to determine differences among gender for continuous variables and the chi-square test was used for categorical variables. The proportion-test were used to perform tests on the equality of proportions using large-sample statistics. To compare median we used Wilcoxon rank-sum test. We used linear regression models using the minutes walking per week (dependent variable), BMI and self-rated health (independent variables) along with adjustments for age and educational level. Besides, we also applied the logistic regression model (logit) to analyze the association of independent variables and dependent dichotomous variable (walking $<150$ $\mathrm{min} /$ week vs. walking $\geq 150 \mathrm{~min} /$ week). Finally, adjusted odds ratios (OR) with their confidence intervals were estimated using the multivariate regression model. The model was initially adjusted by age and educational level.

We tested the interaction by performing a linear regression with the continuous dependent variable and logistic regression model (logit) with the dichotomous dependent variable. The outcomes had statistical significance. Observations with missing values have been dropped automatically by Stata (StataCorp LP, College Station, USA).
All statistical analysis was performed using Stata for Mac, version 12. Statistical significance was set at $\mathrm{p}$-value $<0.05$.

\section{Ethical aspects}

This analysis was conducted on an unidentified public use dataset with all data kept anonymous. According to Spanish legislation it was not necessary to have the approval of an ethics committee.

\section{Results}

The sample of the Spanish population consisted of 22,188 interviews. For this manuscript, we used data from individuals aged 20 years of age and older (age range: $20-82$ years), totaling 21,486 individuals. Of those, $45.1 \%(\mathrm{n}=9,699)$ were males and $54.9 \%(n=11,787)$ were females. The sample's average age was 52.3 years old (standard deviation $-\mathrm{SD}=18.03$ )

Table 1 shows the descriptive data according to gender. Women were significantly older than men. Men, however, showed higher BMI and were more active (walking) than women (men: 210 minutes/day; women: $180 \mathrm{~min} /$ day; $\mathrm{p}$-value $<0.001)$. Furthermore, data showed the men had better health perceptions than women (male: $6.6 \%$; female: 11.7 ; p-value $<0.001$ ). The prevalence of overweight and obesity was $34.2 \%$ and $12.7 \%$ in women, and $52.1 \%$ and $12.7 \%$ in men, respectively ( $p$-value $<0.001$ for obesity between gender). $53.2 \%$ of women met the recommended levels of PA through walking ( $\geq 150 \mathrm{~min} /$ week) while the corresponding figure for men was $57.5 \%$ ( $\mathrm{p}$-value $<0.001$ ).

Table 2 depicts the prevalence data of meeting the PA recommendation ( $\geq 150$ minutes walking per week). Prevalence is minus for the obese $(49.86 \%)$, and significantly lower in obese females $(45.34 \%)$ than male ( $p$-value $<0.001)$. Also the prevalence is less in females $(31.43 \%)$ with very poor/poor self-rated health compared with males $(38.77 \%)$.

Table 3 depicts the regression analysis with walking (min/week) as a dependent variable. After adjustment for age and education level, our data showed that in both men and women, BMI and self-rated health were significant predictors for walking ( $p$-value $<0.001$ ). Where BMI increases, minutes of walking per week decrease $(b=$ -3.95), more so for men $(b=-4.70)$ than for women $(b=-2.85)$. When self-rated health increases, so too do the minutes of walking per week ( $\mathrm{b}=$ 56.69) (Table 3).

Logistic regression analysis (Table 4) showed that those who were classified as either over- 
Table 1

Participant characteristics: percentage, measures of central trend (mean or median) and statistical dispersion ( $95 \% \mathrm{Cl}$ or IQR).

\begin{tabular}{|c|c|c|c|c|c|c|c|c|c|}
\hline \multirow[t]{2}{*}{ Variable } & \multicolumn{3}{|c|}{ All $(n=21,486)$} & \multicolumn{3}{|c|}{ Male $(n=9,699,41.5 \%)$} & \multicolumn{3}{|c|}{ Female $(n=11,787,54.9 \%)$} \\
\hline & $\mathrm{n}$ & $\begin{array}{l}\text { Mean or } \\
\text { Median }\end{array}$ & $95 \% \mathrm{Cl}$ or IQR & $\mathrm{n}$ & $\begin{array}{c}\text { Mean or } \\
\text { Median }\end{array}$ & $\begin{array}{c}95 \% \mathrm{Cl} \text { or } \\
\mathrm{IOR}\end{array}$ & $\mathrm{n}$ & $\begin{array}{l}\text { Mean or } \\
\text { Median }\end{array}$ & $95 \% \mathrm{Cl}$ or IQR \\
\hline Age (years) & 21,486 & 52.3 & $52.0-52.5$ & 9,699 & 50.5 & $50.2-50.9$ & 11,787 & 53.7 * & $53.4-54.1$ \\
\hline Weight (kg) & 20,676 & 71.9 & $71.7-72.2$ & 9,405 & 79.5 & $79.3-79.8$ & 11,271 & $65.6 *$ & $65.4-65.8$ \\
\hline Height (cm) & 20,346 & 166.1 & $166.0-166.2$ & 9,405 & 172.5 & $172.4-172.7$ & 10,941 & 160.6 * & $160.4-160.7$ \\
\hline Walking & 21,486 & 180 ** & $420 * \star \star$ & 9,699 & 210 ** & $420 * \star \star$ & 11,787 & $180 * \star \star, \#$ & $420 * \star \star$ \\
\hline \multirow[t]{3}{*}{ BMI (kg.m-2) } & 19,924 & 26.0 & $25.9-26.1$ & 9,253 & 26.7 & $26.6-26.8$ & 10,671 & 25.4 * & $25.3-25.5$ \\
\hline & \multicolumn{3}{|c|}{ All } & \multicolumn{3}{|c|}{ Male } & \multicolumn{3}{|c|}{ Female } \\
\hline & $\mathrm{n}$ & $\begin{array}{l}\text { Percent } \\
\text { Mean }\end{array}$ & $95 \% \mathrm{Cl}$ & $\mathrm{n}$ & $\begin{array}{l}\text { Percent } \\
\text { Mean }\end{array}$ & $95 \% \mathrm{Cl}$ & $\mathrm{n}$ & $\begin{array}{l}\text { Percent } \\
\text { Mean }\end{array}$ & $95 \% \mathrm{Cl}$ \\
\hline \multicolumn{10}{|l|}{ BMI (categorical) } \\
\hline \multirow[t]{2}{*}{ Normal } & 8,923 & 44.8 & $44.0-45.4$ & 3,355 & 35.2 & $34.2-36.1$ & 5,668 & 53.1 & $52.1-54.0$ \\
\hline & & 22.3 & $22.3-22.4$ & & 22.9 & $22.9-23.0$ & & $21.9 \# \#$ & $21.9-22.0$ \\
\hline \multirow[t]{2}{*}{ Overweight } & 8,468 & 42.5 & $41.8-43.2$ & 4,819 & 52.1 & $51.0-53.1$ & 3,649 & 34.2 & $33.2-35.0$ \\
\hline & & 27.5 & $27.5-27.6$ & & 27.5 & $27.5-27.6$ & & 27.5 & $27.5-27.6$ \\
\hline \multirow[t]{3}{*}{ Obesesity } & 2,533 & 12.7 & $12.2-13.1$ & 1,179 & 12.7 & $12.1-13.4$ & 1,354 & 12.7 & $12.0-13.3$ \\
\hline & & 34.1 & $33.9-34.2$ & & 33.7 & $33.5-33.9$ & & 34.4 \#\# & $34.2-34.6$ \\
\hline & $n$ & Percent & $95 \% \mathrm{Cl}$ & $n$ & Percent & $95 \% \mathrm{Cl}$ & $\mathrm{n}$ & Percent & $95 \% \mathrm{Cl}$ \\
\hline \multicolumn{10}{|l|}{ Self-rated health } \\
\hline Very poor/Poor & 2,021 & 09.4 & $09.1-09.7$ & 637 & 06.6 & 06.0-07.0 & 1,384 & $11.7 \# \#$ & $11.1-12.3$ \\
\hline Fair & 4,692 & 21.8 & $21.2-22.3$ & 1,817 & 18.7 & $17.9-19.5$ & 2,875 & $24.4 \# \#$ & $23.6-25.2$ \\
\hline $\begin{array}{l}\text { Good/Very } \\
\text { good }\end{array}$ & 14,773 & 68.8 & 68.1-69.4 & 7,245 & 74.7 & $73.8-75.5$ & 7,528 & 63.9 \#\# & $62.9-64.7$ \\
\hline \multicolumn{10}{|l|}{ Walking } \\
\hline Yes: > 150 & 21,486 & 55.2 & $54.5-55.8$ & 9,699 & 57.5 & $56.5-58.5$ & 11,787 & 53.2 \#\#\# & $52.3-54.1$ \\
\hline
\end{tabular}

95\% Cl: 95\% confidence interval; BMI: body mass index;

${ }^{*} \mathrm{p}<0.001$, t-test;

** Median;

*** IQR: interquartile range;

\# p-value < 0.001, Wilcoxon rank-sum test;

\#\# p-value $<0.001$, chi-square;

\#\#\#-value $<0.001$, proportion-test.

weight or obese were more likely to be classified as a low-level walker $(\mathrm{OR}=0.82$, $\mathrm{p}$-value $<0.001$ for men; $\mathrm{OR}=0.72, \mathrm{p}$-value $<0.05$ for women) compared to their peers of a normal weight, even after adjustment for age and educational level. Women who rated their health as fair $(\mathrm{OR}=2.16$, $\mathrm{p}$-value $<0.05)$ and good/very good $(\mathrm{OR}=2.82$, $\mathrm{p}$ value $<0.05$ ) were more likely to meet the recommended levels of PA through walking compared to their peers who perceived their health to be poor, while for men the corresponding figure was $\mathrm{OR}=2.46$ for fair health and $\mathrm{OR}=1.79$ for good $/$ very good.

\section{Discussion}

Although there are some studies that address the association of walking and some health outcomes such as BMI and self-rated health 21 , to 
Prevalence of physical activity status (walking 150 minutes per week or more) by gender.

\begin{tabular}{|c|c|c|c|c|c|c|c|c|c|}
\hline & \multicolumn{3}{|c|}{ All } & \multicolumn{3}{|c|}{ Male } & \multicolumn{3}{|c|}{ Female } \\
\hline & $\mathrm{n}$ & PPA & $95 \% \mathrm{Cl}$ & $\mathrm{n}$ & PPA & $95 \% \mathrm{Cl}$ & $\mathrm{n}$ & PPA & $95 \% \mathrm{Cl}$ \\
\hline \multicolumn{10}{|l|}{ BMI (categorical) } \\
\hline Normal & 8,923 & 57.19 & $56.76-58.81$ & 3,255 & 58.55 & $56.85-60.23$ & 5,668 & 57.35 * & $56.06-58.63$ \\
\hline Overweight & 8,468 & 57.17 & $56.12-58.23$ & 4,819 & 59.38 & $57.99-60.76$ & 3,649 & 54.26 ** & $52.64-55.87$ \\
\hline Obese & 2,533 & 49.86 & $47.91-51.80$ & 1,179 & 55.04 & $52.18-57.87$ & 1,354 & 45.34 ** & $42.70-48.01$ \\
\hline \multicolumn{10}{|l|}{ Self-rated health } \\
\hline Very poor/Poor & 2,021 & 33.74 & $31.71-35.83$ & 637 & 38.77 & $35.05-42.63$ & 1,384 & $31.43 * \star$ & $29.03-33.92$ \\
\hline Fair & 4,692 & 54.51 & $53.08-55.93$ & 1,817 & 59.98 & $57.71-62.22$ & 2,875 & 51.06 ** & $49.23-52.88$ \\
\hline Good/Very good & 14,773 & 58.32 & $57.53-59.12$ & 7,245 & 58.56 & $57.42-59.69$ & 7,528 & $58.10 * \star \star$ & $56.98-59.21$ \\
\hline
\end{tabular}

95\% Cl: 95\% confidence interval; PPA: proportion of individuals walking for 150 minutes per week or more.

${ }^{*}$ p-value $=0.269$, proportion-test;

** $p$-value $<0.001$, proportion-test;

${ }^{\star * \star} \mathrm{p}$-value $=0.569$, proportion-test.

Table 3

Linear regression models for walking (continuous variable minutes per week).

\begin{tabular}{|c|c|c|c|c|}
\hline Variable to explain & Variables included & b & $s x^{-}$ & $p$-value \\
\hline Walking (min/week) & Constant & 309.91 & 24.72 & $<0.001$ \\
\hline \multirow[t]{2}{*}{ All } & BMI & -3.95 & 0.67 & $<0.001$ \\
\hline & Self-rated health & 56.69 & 4.93 & $<0.001$ \\
\hline Walking (min/week) & Constant & 400.62 & 43.89 & $<0.001$ \\
\hline \multirow[t]{2}{*}{ Male } & BMI & -4.70 & 1.24 & $<0.001$ \\
\hline & Self-rated health & 56.77 & 8.88 & $<0.001$ \\
\hline Walking (min/week) & Constant & 287.08 & 28.41 & $<0.001$ \\
\hline \multirow[t]{2}{*}{ Female } & BMI & -2.85 & 0.73 & $<0.001$ \\
\hline & Self-rated health & 55.13 & 5.45 & $<0.001$ \\
\hline
\end{tabular}

Linear regression models were adjusted for educational level and age.

BMI: body mass index (kg.m-2).

the best of our knowledge, this is one of the first ones that was carried out among a representative sample of the Spanish adult population 22 . Data in the present study showed that the prevalence of overweight and obesity was $34.2 \%$ and $12.7 \%$ in women, and $52.1 \%$ and $12.7 \%$ in men, respectively. Although our findings were self-reported, the prevalence of overweight and obesity among Spaniards is higher than the average values obtained by self-report in European countries (overweight: $25.6 \%$ in women and $36.6 \%$ in men; obesity: $10.1 \%$ in women and $9 \%$ in men) 23 and the Portuguese population 24. The higher prevalence of overweight/obese men compared with women is consistent with previous findings in the USA and Europe 5,25, suggesting the need for tailored strategies aimed at obesity reduction and physical activity promotion.

In our study, the compliance with meeting the recommended levels of PA through walking ( $\geq 150 \mathrm{~min} /$ week) was $57.5 \%$ for men and $53.2 \%$ for women. Bamana et al. 26 also found a higher prevalence in men than women to meet the physical activity recommendations. As men- 
Association (OR; 95\% Cl) between BMI, self-rated health and walking 150 minutes per week or more, by gender.

\begin{tabular}{|c|c|c|c|}
\hline Variable & All OR (95\%Cl) & Male OR $(95 \% \mathrm{Cl})$ & Female OR $(95 \% \mathrm{Cl})$ \\
\hline \multicolumn{4}{|l|}{ BMI (categories) } \\
\hline Normal & 1.00 & 1.00 & 1.00 \\
\hline Overweight & $0.93 *(0.87-0.99)$ & $0.95(0.86-1.04)$ & $0.94(0.86-1.03)$ \\
\hline Obese & $0.75 * *(0.68-0.82)$ & $0.82^{\star \star \star}(0.71-0.94)$ & $0.72 * \star(0.64-0.82)$ \\
\hline \multicolumn{4}{|c|}{ Self-rated health (self-reported) } \\
\hline Very poor/Poor & 1.00 & 1.00 & 1.00 \\
\hline Fair & 2.33 ** $(2.07-2.62)$ & 2.46 ** $(2.02-3.00)$ & 2.16 ** $(1.87-2.51)$ \\
\hline Good/Very good & $2.85 * *(2.55-3.20)$ & $2.79 * \star(2.31-3.36)$ & 2.82 ** $(2.44-3.26)$ \\
\hline
\end{tabular}

95\% Cl: 95\% confidence interval; BMI: body mass index (categorical); OR: odds ratio; dependent variable was dichotomy:

$0,<150 \mathrm{~min} /$ week; $1, \geq 150 \mathrm{~min} /$ week. Logistic regression models were adjusted for educational level and age.

* $\mathrm{p}$-value $<0.01$

** $\mathrm{p}$-value $<0.05$;

*** $\mathrm{p}$-value $<0.001$

tioned in other studies 5,27,28,29 men and women in the walking category ( $\geq 150 \mathrm{~min} /$ week) had smaller OR for obesity, supporting the idea that regular physical activity may be associated with lower risk of overweight and obesity 9,26,30. This is important because in our study, this association remained significant even after adjustment for educational level and age. Indeed, previous studies have shown an inverse association between BMI and educational level, where low SES individuals reported less leisure time PA and were less likely to consume healthy or low-fat diets 21,31 . Further, our results were similar to other studies that found that males walk more frequently than females 32,33 . Indeed, The fact that men achieved the highest PA categories more frequently than women has been widely reported, regardless of the method used to measure PA or the domain of PA assessed 34,35 .

Prevalence according to PA status $(\geq 150 \mathrm{~min} /$ week) was higher in overweight/obese males than females in the same category, which was similar to findings reported in other studies that also found that males better meet the recommendations of PA guidelines than females 20 . There was no prevalence differences between individuals of normal weight compared with those who are overweight and of the same gender, but there are differences between overweight and obese 17,20. In addition, there are differences between individuals with self-rated health given as very poor/ poor compared with the rest, particularly among women $17,20,22$.

Education is positively associated with more health-related knowledge 28 and a higher capac- ity to put it into practice 36 . Thus, our data adjusted for those variables (age and educational level) clearly suggest the association of walking (as a marker of physical activity) with obesity and health. This is important, although some studies suggest that the relation between obesity (BMI) and walking raises the importance of intensity rather than volume 37 . Indeed, others have argued that the negative association between physical activity and BMI is restricted to vigorous rather than moderate-intensity activities 38 . While moderate physical activity may be adequate to decrease cardiovascular risk factors and mortality, it may not be sufficient for weight control 36. Nonetheless, in agreement with our findings, previous studies have shown that obese individuals may benefit more from their walking time than normal-weight participants and therefore walking should be encouraged. For instance, Hills et al. 39 proved that though walking slower, obese individuals had a more intense physiological response than normal-weight counterparts even if they "walked for pleasure", which equated with an exercise intensity sufficient to improve cardio-respiratory fitness in obese, but not in normal-weight individuals. Browning \& Kram 40 also showed that walking consumed $11 \%$ more calories among obese women compared to those who are normal-weight, when done at similar speeds, which may imply a greater cardiovascular effort for the obese.

Moreover, the fact that those who rated themselves as "good health" were more likely (males OR $=2.79$ and females $\mathrm{OR}=2.82$; similar outcomes in the linear regression models) to 
be classified as achieving the walking standards, reinforces the association of walking (being active) on perceived health. This is a worthy finding since results have stressed the importance of exercise/walking on mental health, namely on depression 41 . Furthermore, it has long been recognized that a better perceived health is associated with higher quality of life and functionality, which, indeed, preserves higher levels of physical activity. Additionally self-rated health has been an important independent predictor of risk of cardiovascular disease and all-cause mortality 15 . Thus, these findings found in a large and representative population add further evidence towards the idea that regular physical activity is associated with people's perception of overall health 42 .

The strengths of this study include the sample size and country representativeness, which mean that the results can be generalized for the entire Spanish adult population. However, some limitations of this work must be acknowledged. Firstly, our data relies on self-reported variables, which means that respondents, particularly those with higher education may over-report behaviors. Additionally, several studies have shown the limitation of self-reported instruments such as IPAQ to correctly classify individuals according to their physical activity level 43 . The short form of the IPAQ was chosen to measure PA levels in this population, but future studies might consider the use of the long form of this questionnaire, to better understand PA patterns by PA domain (ie: work related PA, transportation PA, housework PA and leisure time PA) 16. Furthermore, the IPAQ combines all forms of walking including leisure time and transportation. This is an important issue because studies have shown that the association between physical activity, well-being and quality of life varies by domain, in particular between leisure time and transportation. This is particularly important for largely urbanized regions of the world that have high levels or density and traffic. In this sense, it is possible that the associations with perceived health might be different if walking for leisure time was analyzed separately from transportation, where people are exposed to traffic and personal safety concerns as well as air and noise pollution 44 . BMI based on self-report data, could indicate an underestimation of the true prevalence of over- weight and obesity 45. Nevertheless, BMI from self-report data was found to be sufficiently accurate and widely used in epidemiological studies, since objective measurements of weight and height in large samples can be difficult and unaffordable. Physical activity assessed by self-report data is not as precise as more objective methods such as accelerometers, but questionnaires have acceptable validity and reliability for population studies, particularly when the intention is to differentiate those with high vs. low physical activity levels ${ }^{2}$. Lastly, this is a cross-sectional study and therefore the direction of the association between walking and the other variables cannot be assumed. Further improvements on research focused on determinants with improved causal inference (longitudinal studies) which might reinforce such cross-sectional data. Another limitation is that it was not possible to include in this study variables related with health or individual habits that may influence the PA, such as social class, alcohol consumption or smoking.

The results of this study show, in many cases, p-values below 0.001 , as well as that some measures of association were very small. This may arise because the sample size is very large. Despite the limitations, our findings drawn from a population-based surveillance study add evidence to support suggestions that regular walking in adults is associated with better health perceptions as well as a better BMI profile.

\section{Conclusions}

In conclusion, the data drawn from a large and representative data set of population-based surveillance study give additional evidence to support suggestions that regular walking in adults is associated with better health perceptions as well as a better BMI profile and the individuals with obesity and very poor/poor self-rated health show less prevalence of walking. The findings of this study support the need to advise and motivate adults towards the integration of regular walking into their lifestyle. From a public health perspective, this population-based study suggests that the strategies that promote PA in communities may benefit adults' overall health and well-being. 


\section{Contributors}

V. Romo-Perez had the idea of the investigation, carried out the statistical analysis and wrote the article. D. Souto and J . Mota contributed to the data analysis and wrote the article.

\section{References}

1. Warburton DER, Nicol CW, Bredin SSD. Health benefits of physical activity: the evidence. Can Med Assoc J 2006; 174:801-9.

2. Katzmarzyk PT, Janssen I, Ardern CI. Physical inactivity, excess adiposity and premature mortality. Obes Rev 2003; 4:257-90.

3. Tessier S, Vuillemin A, Bertrais S, Boini S, Le Bihan E, Oppert JM. Association between leisure-time physical activity and health related quality of life changes over time. Prev Med 2007; 44:202-8.

4. Lee IM, Shiroma EJ, Lobelo F, Puska P, Blair SN, Katzmarzyk PT. Effect of physical inactivity on major non-communicable diseases worldwide: an analysis of burden of disease and life expectancy Lancet 2012; 380:219-29.

5. Kohl HW, Craig CL, Lambert EV, Inoue S, Alkandari JR, Leetongin G, et al. The pandemic of physical inactivity: global action for public health. Lancet 2012; 380:294-305.

6. World Health Organization. Global recommen dations on physical activity for health, January. http://www.who.int/dietphysicalactivity/factsheet recommendations/en/ (accessed on 29/Jul/2014).

7. Hallal PC, Andersen LB, Bull FC, Guthold R, Haskell W, Ekelund U. Global physical activity levels: surveillance progress, pitfalls, and prospects. Lancet 2012; 380:247-57.

8. TNS Opinion \& Social. Sport and physical activity. Brussels: TNS Opinion \& Social/European Commission; 2010. (Special Eurobarometer, 334).

9. Fogelholm M, Stallknecht B, van Baak M. ECSS position statement: exercise and obesity. Eur J Sport Sci 2006; 6:15-24.

10. Gutierrez-Fisac JL, Guallar-Castillon P, Leon-Muñoz LM, Graciani A, Benegas JR, Rodriguez-Artalejo F. Prevalence of general and abdominal obesity in the adult population of Spain, 2008-2010: the ENRICA study. Obes Rev 2012; 13:388-92. 
11. Becerra JM, Reis RS, Frank LD, Ramirez-Marrero FA, Welle B, Cordero EA, et al. Transport and health: a look at three Latin American cities. Cad Saúde Pública 2013; 29:654-66.

12. Besser LM, Dannenberg AL. Walking to public transit steps to help meet physical activity recommendations. Am J Prev Med 2005; 29:273-80.

13. Kitchen P, Williams A, Chowhan J. Walking to work in Canada: health benefits, socio-economic characteristics and urban-regional variations. BMC Public Health 2011; 11:112.

14. Ogilvie D, Mitchell R, Mutrie N, Petticrew M, Platt S. Personal and environmental correlates of active travel and physical activity in a deprived urban population. Int J Behav Nutr Phys Act 2008; 5:43.

15. Mason C, Katzmarzyk PT, Craig CL, Gauvin L. Mortality and self-rated health in Canada. J Phys Act Health 2007; 4:423-33.

16. Jylha M. What is self-rated health and why does it predict mortality? Towards a unified conceptual model. Soc Sci Med 2009; 69:307-16.

17. Fuller D, Pabayo R. The relationship between utilitarian walking, utilitarian cycling, and body mass index in a population based cohort study of adults: comparing random intercepts and fixed effects models. Prev Med 2014; 69:261-6.

18. Instituto Nacional de Estadística. Encuesta Europea de Salud en España: EES-2009. http://www. ine.es/metodologia/t15/t153042009.pdf (accessed on $29 / \mathrm{Jul} / 2014$ ).

19. Garber C, Blissmer B, Deschenes M, Franklin B, Lamonte M, Lee I, et al. Quantity and quality of exercise for developing and maintaining cardiorespiratory, musculoskeletal, and neuromotor fitness in apparently healthy adults: guidance for prescribing exercise. Med Sci Sports Exerc 2011; 43:133459

20. Carlson S, Fulton J, Schoemborn C, Loustalot F. Trend and prevalence estimates based on the 2008 physical activity guidelines for Americans. Am J Prev Med 2010; 39:305-13.

21. Santos R, Santos P, Ribeiro J, Mota J. Physical activity and other lifestyle behaviors in a Portuguese sample of adults: results from the Azorean physical activity and health study. J Phys Act Health 2009; 6:750-9.

22. Martinez-Gómez D, León-Muñoz L, Guallar-Castillón P, López-García E, Aguilera M, Banegas J, et al. Reach and equity of primary care-based counselling to promote walking among the adult population of Spain. J Sci Med Sport 2013; 16:532-8

23. Martinez JA, Kearney JM, Kafatos A, Paquet S, Martinez-Gonzalez MA. Variables independently associated with self-reported obesity in the European Union. Public Health Nutr 1999; 2:125-33.

24. Sardinha LB, Santos DA, Silva AM, Coelho-e-Silva MJ, Raimundo AM, Moreira H, et al. Prevalence of overweight, obesity, and abdominal obesity in a representative sample of Portuguese adults. PLoS One 2012; 7:e47883.
25. Ogden CL, Carroll MD, Curtin LR, McDowell MA, Tabak CJ, Flegal KM. Prevalence of overweight and obesity in the United States, 1999-2004. JAMA 2006; 295:1549-55.

26. Bamana A, Tessier S, Vuillemin A. Association of perceived environment with meeting public health recommendations for physical activity in seven European countries. J Public Health 2008; 30:274-81.

27. Chen Y, Mao Y. Obesity and leisure time physical activity among Canadians. Prev Med 2006; 42: 261-5.

28. Rodriguez-Artalejo F, Lopez E, Gutierrez-Fisac JL, Banegas JR, Lafuente PJ, Domínguez V. Changes in the prevalence of overweight and obesity and their risk factors in Spain, 1987-1997. Prev Med 2002; 34:72-81.

29. Tur JA, Serra-Majem L, Romaguera D, Pons A. Profile of overweight and obese people in a Mediterranean region. Obes Rev 2005; 13:527-36.

30. So W, Choi D. Differences in physical fitness and cardiovascular function depend on BMI in korean men. J Sports Sci Med 2010; 9:239-44.

31. Smith AM, Owen N. Associations of social status and health-related beliefs with dietary fat and fiber densities. Prev Med 1992; 21:735-45.

32. Eyler A, Brownson RC, Bacak SJ, Housemann RA. The epidemiology of walking for physical activity in the United States. Med Sci Sports Exerc 2003; 35:1529-36.

33. Fitzhugh E, Thompson DL. Leisure-time walking and compliance with ACSM/AHA aerobic-related physical activity recommendations: 1999-2004 NHANES. J Phys Ac Health 2009; 6:393-402.

34. Harrison RA, McElduff P, Edwards R. Planning to win: health lifestyles associated with physical activity amongst 15,423 adults. Public Health 2006; 120:206-12.

35. Sjöström M, Oja P, Hagströmer M, Smith BJ, Bauman A. Health-enhancing physical activity across european union countries: the eurobarometer study. J Public Health 2006; 14:291-300.

36. Slootmaker SM, Schuit AJ, Chinapaw M, Seidell J, Mechelen W. Disagreement in physical activity assessed by accelerometer and self-report in subgroups of age, gender, education and weight status. Int J Behav Nutr Phys Act 2009; 6:17.

37. Brill JB, Perry AC, Parker L, Robinson A, Burnett K. Dose-response effect of walking exercise on weight loss. How much is enough? Int J Obesity 2002; 26:1484-93.

38. Bernstein MS, Costanza MC, Morabia A. Association of physical activity intensity levels with overweight and obesity in a population-based sample of adults. Prev Med 2004; 38:94-104.

39. Hills AP, Byrne NM, Wearing S, Armstrong T. Validation of the intensity of walking for pleasure in obese adults. Prev Med 2006; 42:47-50.

40. Browning RC, Kram R. Energetic cost and preferred speed of walking in obese vs. normal weight women. Obes Res 2005; 13:891-9. 
41. Blumenthal J, Babyak M, Doraiswamy P, Watkins L, Hoffman B, Barbour K, et al. Exercise and pharmacotherapy in the treatment of major depressive disorder. Psychosom Med 2007; 69:587-96.

42. Tsai J, Ford ES, Li C, Zhao G, Balluz LS. Physical activity and optimal self-rated health of adults with and without diabetes. BMC Public Health 2010; 10:365.

43. Ekelund U, Sepp H, Brage S, Becker W, Jakes R, Hennings $M$, et al. Criterion-related validity of the last 7-day, short form of the International Physical Activity Questionnaire in Swedish adults. Public Health Nutr 2006; 9:258-65.

\section{Resumen}

Obesidad e inactividad física son factores de riesgo para enfermedades crónicas, que están asociados a estilos de vida y factores ambientales. El objetivo fue establecer la asociación entre inactividad física, indice de masa corporal (IMC) y autopercepción de salud. La muestra representativa está formada por población adulta española compuesta por 21.486 participantes. Siendo un 41.5\% hombres, media de edad 52,3 años $( \pm 18,03)$ y variación de edad de $20-82$ años. La prevalencia de sobrepeso/obesidad fue $34,2 \% / 12,7 \%$ en las mujeres y 52,1\%/12,7\% en los hombres ( $p<0,001$ para la obesidad entre los sexos). Entre los evaluados 53\% de las mujeres y un 57,5\% de los hombres atienden los niveles recomendados de actividad física mediante caminatas ( $\geq 150$ minutos/semana). El análisis de regresión logística mostró que los que caminan poco poseen mayor riesgo de sufrir sobrepeso o ser obesos. Los datos extraídos del estudio de vigilancia de base poblacional apoyan las premisas de que las caminatas regulares en adultos están asociadas a la percepción positiva de salud y un mejor perfil de IMC. Quienes sufren obesidad y baja/muy baja autopercepción de salud cuentan con menos prevalencia para atender las recomendaciones.

Ejercicio; Identidad de Género; Actividad Motora; Adulto
44. Jurakić D, Pedišić Z, Greblo Z. Physical activity in different domains and health-related quality of life: a population-based study. Qual Life Res 2010; 19:1303-9

45. Yun S, Zhu BP, Black W, Brownson RC. A comparison of national estimates of obesity prevalence from the behavioral risk factor surveillance system and the National Health and Nutrition Examination Survey. Int J Obesity 2006; 30:164-70.

\section{Resumo}

Obesidade e inatividade física são fatores de risco para doenças crônicas, estão associadas a estilos de vida e fatores ambientais. O objetivo foi estabelecer a associação entre inatividade física, índice de massa corporal (IMC) e autopercepção de saúde. A amostra representativa da população adulta espanhola foi composta por 21.486 participantes, sendo $41.5 \%$ homens, média de idade 52,3 anos $( \pm 18,03)$ e variação etária de 20 a 82 anos. A prevalência de sobrepeso/obesidade foi $34,2 \% / 12,7 \%$ nas mulheres e $52,1 \% / 12,7 \%$ nos homens ( $p<0,001$ para a obesidade entre os sexos). Dentre os avaliados, $53 \%$ das mulheres e 57,5\% dos homens atendem aos niveis recomendados de atividade física por meio da caminhada $(\geq 150$ minutos/ semana). A análise de regressão logística mostrou que os que caminham pouco possuem maior risco de estar acima do peso ou serem obesos. Os dados extraídos do estudo de vigilância de base populacional suportam sugestões que caminhadas regulares em adultos estão associadas à percepção positiva de saúde e melhor perfil de IMC. Obesidade e baixa/muito baixa autopercepção de saúde têm menos prevalentes para atender às recomendações.

Exercício; Identidade de Gênero; Atividade Motora; Adulto
Submitted on $07 /$ Nov/2014

Final version resubmittedv on 31/Jul/2015

Approved on 27/Ago/2015 